\title{
MARCACIONES URBANAS EN MEMORIA DE LOS TRABAJADORES
} URBAN MARKINGS IN MEMORY OF THE WORKERS

Pablo Ungaro | ungaro2001@yahoo.com.ar Mariano Aguyaro |agu_mj@yahoo.com.ar

Laboratorio de Investigaciones y Desarrollo del Diseño Industrial. Facultad de Bellas Artes. Universidad Nacional de La Plata. Argentina

Recibido: 11/2/2019 | Aceptado: 13/5/2019

\section{RESUMEN}

Se describirán brevemente los objetivos y las finalidades del proyecto de investigación «Marcaciones Urbanas en memoria de los trabajadores bancarios» enmarcado en el Laboratorio de Investigaciones y Desarrollo del Diseño Industrial de la Facultad de Bellas Artes de la Universidad Nacional de La Plata.

\section{PALABRAS ClaVe}

Diseño; memoria; marcaciones urbanas

\section{ABSTRACT}

The objectives and purposes of the research project «Urban Marking in memory of bank workers» framed in the Industrial Design Research and Development Laboratory of the Faculty of Fine Arts of the National University of La Plata will be briefly described.

\section{KEYWORDS}

Design; memory; urban markings 
Desde la disciplina del Diseño Industrial nos preguntamos qué podemos hacer para resistir los embates del neoliberalismo en la Argentina que no solamente rompe el entramado productivo que contiene a nuestra profesión, sino que también niega luchas históricas que costaron décadas de dedicación militante. Creemos que desde nuestra disciplina se puede contribuir a potenciar la lucha por Memoria, la Verdad y la justicia y, de esta manera, resistir a las políticas negacionistas del gobierno de Cambiemos.

El proyecto "Marcaciones Urbanas en Memoria de los trabajadores bancarios» obtuvo el apoyo el Fondo Nacional de las Artes (FNA) y se lleva adelante desde el Laboratorio de Investigaciones y Desarrollo del Diseño Industrial (LIDDI) de la Facultad de Bellas Artes (FBA) de la Universidad Nacional de La Plata (UNLP), en colaboración con el Doctorado en Historia de la Facultad de Humanidades y Ciencias de la Educación (FHCE) de la UNLP. El gremio de trabajadores bancarios La Bancaria es responsable y promotor del proyecto en la figura de Sergio Palazzo y de Claudia Ormachea.

El terrorismo de estado en la Argentina, que dejó más de treinta mil detenidos/ desaparecidos, se ensañó particularmente contra los trabajadores y sus organizaciones. En ese sentido, los trabajadores bancarios sufrieron amedrentamiento, persecuciones, detenciones, torturas, asesinatos y desapariciones. Se calcula que cerca de doscientos trabajadores bancarios de todo el país padecieron estas penurias, que constituyen delitos de lesa humanidad, en manos del aparato represivo estatal.

En la Argentina, a raíz de estos terribles acontecimientos, surgieron organismos defensores de los derechos humanos que hoy son como ejemplos a nivel mundial en la lucha por la Memoria, la Verdad y la Justicia. Esta militancia y el consenso colectivo promovieron, en muchísimas organizaciones, comisiones por lo Memorio. La Bancaria cuenta, desde hace muchos años, con una Secretaria y una Prosecretaria de Derechos Humanos, que son las responsables, en asociación con otras instituciones complementarias, del presente proyecto.

En todo el país se han realizado homenajes que dejan registros físicos a través de obras artísticas, memoriales, monumentos, placas y señalamientos que dan cuenta de la magnitud del genocidio. Sin embargo, solo unas pocas de estas acciones se constituyeron en un «sistema de marcación» nucleado bajo un mismo concepto y una misma estética. En este sentido, se destacan las iniciativas populares de Barrios x la Memoria y la Justicia y Baldosas Blancas de la memoria, hacio una cartografía de la Memoria Platense (Ungaro, 2012), este último proyecto quedó radicado en el LIDDI hace ya tres años.

También se han desarrollado plataformas de comunicación a través de diversos medios, entre ellos Internet. Se destaca, en ese sentido, Baldosas Blancas de la Memoria, de donde tomamos algunos conceptos básicos, y la plataforma Arqueología de las Ausencias. Memoria y archivo de los trabajadores bancarios Detenidos Desaparecidos.

Que el propio colectivo de trabajadores bancarios a través de su organización gremial realice acciones reivindicatorias de la vida y la militancia de los compañeros 
detenidos desaparecidos son acciones reparatorias ante el conjunto de los allegados, sus instituciones y la sociedad en general. Paralelamente, el proyecto propone la participación de representantes del Estado que se apersonen a estos actos reparatorios para - en nombre del Estado- pedir "perdón» ante los familiares y los amigos, los organismos de derechos humanos y las organizaciones gremiales. De esta manera, entendemos que se contribuye a la reparación simbólica de estos crímenes: que este colectivo diga bien fuerte NUNCA MÁS el Estado reprimiendo trabajadores.

El objetivo general del proyecto es contribuir a la reparación simbólica de los crímenes de lesa humanidad donde hubo víctimas entre los trabajadores bancarios en cualquier lugar del país. A su vez, entre los objetivos específicos se pueden señalar los siguientes: señalizar dos sitios simbólicos (uno principal y otro secundario) por cada detenido desaparecido de los trabajadores bancarios: la sucursal donde desarrollaba sus tareas y el lugar donde fuera secuestrado; vincular estos dos sitios a través de una cartografía digital; unir el pasado y el presente generando en la marca física un código QR que, al escanearlo con el celular, nos remita a un link de la página Arqueología de la memoria, donde se concentran una mayor cantidad de datos sobre la víctima que las que puede soportar una limitada marcación física. De esta manera, creemos vincular el pasado con el presente de modo dinámico y establecer paralelamente una estrategia de comunicación efectiva.

\section{LA MARCA FÍSICA Y LA METODOLOGÍA}

A partir de las entrevistas e intercambios con los representantes de las instituciones participantes se llegó a proponer un sistema de marcas físicas que se comporte de modo versátil pero que permita una lectura en común a todos los señalamientos urbanos en cada punto del país. Para ello, se propuso trabajar con cintas de acero inoxidable, por sus ventajas comparativas respecto a otros materiales, que nos permitan adaptarnos a las distintas situaciones de emplazamiento que se vayan proponiendo a lo largo del desarrollo del proyecto y que contengan, al menos, los siguientes datos: datos filiatorios de la víctima (Nombre y apellido, edad al momento del crimen); según cada caso y en función de lo que se determine con los organizadores y los familiares, fotografía de la víctima; categoría: secuestrado/desaparecido u asesinado; datos de su militancia: pertenencia a organizaciones políticas; fecha de la desaparición/ asesinato; memoria - verdad - justicia; eventualmente, otros contenidos que se estipule con los organizadores, los familiares o los amigos de cada trabajador en particular.

Una vez seleccionado cada caso en particular, los organizadores toman contacto con los familiares y amigos de las víctimas para consensuar algunas cuestiones representativas que hacen a la identidad de la víctima. Estipulados estos contenidos, se procede al diseño de la marca física (desde el LIDDI) en un ida y vuelta con los organizadores, hasta lograr un acuerdo final que contemple las distintas posiciones de los actores sociales intervinientes siguiendo los lineamientos conceptuales y 
físicos preestablecidos en el sistema de marcación. Paralelamente, se determinan los lugares exactos donde serán colocadas las marcas.

Para el diseño y la producción de la marca se utilizan distintas técnicas digitales y de control numérico. Se produce la marcación en acero inoxidable, material que soporta las inclemencias del tiempo y no se deteriora, alimentando la idea de Memoria. Una vez realizadas las marcas, se colocan es sus sitios específicos y se realizan los preparativos para el acto de homenaje.

\section{Primera marcación uRbana El CaSo SCHWARTZ}

Según el registro de Arqueología de las Ausencios, Julio César Schwartz Seijas, de 39 años, trabajador del Banco Nación, fue secuestrado el 1 de abril de 1974 a trescientos metros de su domicilio en la localidad de El Bolsón y permanece desaparecido. Los compañeros dirigentes de La Bancaria, presentes en el territorio, impulsan la realización de una primera marca urbana en la puerta del Banco Nación de San Carlos de Bariloche. Proponen intervenir en un lugar existente, un cantero circular frente a la sucursal bancaria donde se desempeñaba Julio César.

No obstante, se nos informa que si bien Julio César trabajaba en Bariloche su secuestro se produjo en la localidad de El Bolsón, por lo que se propone la realización de dos marcas conectadas (El Bolsón y Bariloche). Desde el punto de vista del diseño, optamos por que la marca destinada a El Bolsón «naciera» de la marca principal de Bariloche. Realizamos los primeros bocetos y, como práctica participativa, los presentamos a los actores territoriales que fueron modificando la propuesta original hasta llegar a un acuerdo de pieza final. Luego, hicimos los ajustes pertinentes en función de las técnicas de fabricación y de montaje. La marca lleva los datos estipulados y las imágenes. Parte de la producción de la marca física se realizó en La Plata y parte en Bariloche, donde cabe destacar el alto grado de compromiso demostrado por trabajadores de La Bancaria presentes en el territorio.

El 4 de diciembre de 2018, con la participación del secretario General de La Bancaria, Sergio Palazzo, los hijos de Julio César (Adriana y Germán), los dirigentes de la CGT y otros gremios (Unter, Comercio, UPCN) así como la APDH y la organización HIJOS dieron por inaugurado el pequeño memorial. Se prevé que durante 2019 realizaremos dos marcaciones urbanas de casos a definir.

\section{REFERENCIAS}

Arqueología de las Ausencias (2019). [Página web]. Disponible en http://www. arqueologiaausencia.com.ar/

Ungaro, P. (2012). Diseño para la memoria, hacia una cartografía platense. Tableros, 2(3), 14-19. Recuperado de http://sedici.unlp.edu.ar/handle/10915/42997 